IFN Working Paper No. 1189, 2017

\title{
Who Creates Jobs and Who Creates Productivity? Small versus Large versus Young versus Old
}

Fredrik Heyman, Pehr-Johan Norbäck and Lars Persson 


\title{
Who Creates Jobs and who Creates Productivity? Small versus Large versus Young versus Old *
}

\author{
Fredrik Heyman \\ Research Institute of Industrial Economics \\ Pehr-Johan Norbäck \\ Research Institute of Industrial Economics \\ Lars Persson \\ Research Institute of Industrial Economics and CEPR
}

\begin{abstract}
This paper examines employment and productivity dynamics in the Swedish business sector during the period 1996-2013. In order to analyze employment and productivity in a consistent way we apply a novel implementation of a method, which previously has been used extensively to analyze job dynamics, on both job and productivity dynamics. Our results, based on detailed matched employer-employee data for Sweden, indicate substantial heterogeneity in terms of job and productivity dynamics for different types of firms. We find that most of the net jobs were created in young, small firms, but at the same time we also find that most of the productivity gains were created in large old incumbent firms, thus suggesting a division of labor between the two. Our analysis provides new insights into the importance of age and size of firms in the restructuring process, stressing the dichotomy between employment growth and productivity growth in different types of firms.
\end{abstract}

JEL: J23; E24; L16; L25; L26

Keywords: job dynamics; productivity; matched employer-employee data; industrial structure and structural change

\footnotetext{
*The authors can be reached at fredrik.heyman@ifn.se, pehr-johan.norback@ifn.se and lars.persson@ifn.se. Acknowledgements: Charlotta Olofsson and Fredrik Andersson provided excellent research assistance. Financial support from the Marianne and Marcus Wallenberg Foundation is gratefully acknowledged. Fredrik Heyman gratefully acknowledges financial support from the Swedish Research Council for Health, Working Life and Welfare (FORTE), Torsten Söderbergs Stiftelse, the Jan Wallander and Tom Hedelius Research Foundation and Johan och Jakob Söderbergs Stiftelse. Pehr-Johan Norbäck and Lars Persson gratefully acknowledge financial support from the Jan Wallander and Tom Hedelius Research Foundation and Vinnova.
} 


\section{Introduction}

By now, the literature on job and firm dynamics has accumulated substantial knowledge of the restructuring process in the business sector by studying labor market dynamics in terms of labor reallocation and employment dynamics (see e.g. important contributions by Steven Davis, John Haltiwanger and co-authors and references therein). The knowledge of how labor market dynamics and productivity dynamics interact is however more scarce. This paper contributes by using a novel implementation of the so-called Davis et al. methodology on gross job flows to analyze both job and productivity dynamics in a consistent way (see Davis et al., 1997). In short, we apply a similar method that has been extensively used to analyze gross job creation and job destruction on productivity dynamics. Our framework is also closely related to the literature that decomposes overall productivity into different sub-components (see Griliches and Regev, 1995, Foster et al., 2001 and Jeon and Miller, 2005). Our analysis provides new insights into the importance of age and size of firms in the restructuring process, e.g. documenting systematic differences across firms of different size and age in terms of their overall contribution to employment and productivity dynamics. ${ }^{1}$

We apply this novel approach to Swedish matched employer-employee data over the period 1996-2013. Sweden is one of few countries in Europe that has shown both high productivity and job growth in the last few decades (OECD, 2013). In the early 1990s, Sweden faced its most severe economic crisis in the post-war period when Swedish companies lost their competitiveness in the world market. To make its way back, Sweden implemented a wide package of microeconomic reforms aiming at restructuring the economy. ${ }^{2}$ These reforms induced an industrial reorganization process where new and small firms got a chance to play a more important role in the Swedish business sector. This industrial reorganization process was further strengthened by Sweden being one of the first countries in the world to achieve a full-scale implementation of information and communications technologies (ICT) in its business sector.

Extending the Davis et al. methodology on job dynamics to productivity dynamics we find results that indicate a high degree of heterogeneity in terms of both job and productivity dynamics between firms with different size and different age. In line with a large literature on job dynamics, we find that most of the net jobs were created in small firms but, at the same time, we also find

\footnotetext{
${ }^{1}$ Haltiwanger et al. (2016) use U.S. data to examine both job and output (real revenue) dynamics of young high growth firms. They find that patterns for high output growth firms largely mimic those for high employment growth firms. High growth output firms are disproportionately young and make disproportionate contributions to output growth.

${ }^{2}$ Macro-economic reforms were also undertaken including adopting a flexible exchange rate and an independent central bank with an inflation target.
} 
that most of the productivity gains were created in large firms, thus suggesting a division of labor between the two. Importantly, when we also take firm age into account, we find that it is small, young firms that create most of the new employment, whereas it is the old, large firms that generate most of the increase in productivity. We also find that relatively small changes in net value added creation mask large values of gross value added creation and gross value added destruction. This result mirrors findings in the large literature on gross job flows.

\section{Extending the Davis et al. (1997) methodology to both job and productivity dynamics}

We will study how the Swedish restructuring process influenced the combined job and productivity dynamics process. Starting with jobs, we apply the method for studying the job dynamics described in detail in Davis et al. (1997). The method allows us to observe which type of gross job flows that drives a given change in net employment by decomposing aggregate employment changes into their underlying components. Using this concept, we obtain measures of job creation, job destruction, and total job reallocation and observe how they are related to net employment changes. Because we are interested in both job creation and value added creation (productivity growth) and how they interact, we extend this method to productivity dynamics. To our knowledge, this implementation of the Davis et al. methodology for job dynamics has not previously been applied to also analyze productivity dynamics. Our analysis of productivity dynamics is also closely related to the literature that decompose overall productivity into different sub-components. These papers, based on different decomposition methodologies, typically decompose productivity growth into the relative contribution of (i) a within-firm effect, reflecting the importance of continuing firms, (ii) a between-firm effect, and (iii) entry and exit of firms. ${ }^{3}$

By explicitly analyzing how net productivity is related to value creation and value destruction in different types of firms, we present new evidence on how job and productivity dynamics are related. More precisely, we will in a consistent manner compare job and productivity dynamics and how these differ across firm size and firm age. In the following, we give a brief description of the methodology, referring to the Appendix A for details.

\footnotetext{
${ }^{3}$ See Foster et al. (2001) for an extensive discussion of different decomposition methods. See also Syverson (2011) for a survey on the determinants of productivity dynamics, including the use of different accounting decomposition. Jeon and Miller (2005) present a decomposition method that analyse productivity differences across different US states.
} 


\subsection{Job creation and job destruction and net job creation}

Firms belong to groups, in terms of size or age. Let $G$ be the number of groups and let $g$ denote an individual group. Job Creation at time $t, J C_{t}$, is then derived by summing job creation from expanding firms (stayers) and new entrants in all groups, $J C_{g t}$ :

$$
J C_{t}=\sum_{g=1}^{G} \underbrace{\left(\sum_{i=1}^{n_{g t}^{\text {Stay }}}\left[\Delta E_{i g t} \mid \Delta E_{i g t} \geq 0\right]+\sum_{i=1}^{n_{g t}^{\text {Entry }}} E_{i g t}\right)}_{J C_{g t}: \text { job creation in group } g \text { at time } t}
$$

In Equation (1), the first sum within the brackets gives employment creation from expanding firms i.e., $\Delta E_{i g t}=E_{i g t}-E_{i g t-1}>0$, where $E_{i g t}$ denotes a firm's employment in time $t$ and $E_{i g t-1}$ the employment in $t-1$. The second sum within the brackets shows new employment in firms that enter the market. ${ }^{4}$

Similarly, Job Destruction in a given point in time $t, J D_{t}$ is derived by summing job destruction from contracting firms (stayers) and exiting firms in all groups, $J D_{g t}$ :

$$
J D_{t}=\sum_{g=1}^{G} \underbrace{\left(\sum_{i=1}^{n_{g t}^{\text {Stay }}}\left[-\Delta E_{i g t} \mid \Delta E_{i g t}<0\right]+\sum_{i=1}^{n_{g t-1}^{E x i t}} E_{i g t-1}\right)}_{J D_{g t}: \text { job destruction in group } g \text { at time } t}
$$

In Equation (2), the first sum within the brackets gives employment destruction from contracting firms at time $t$. The second sum within the brackets shows reduction in employment in firms that leave the market at $t-1 .{ }^{5}$ Net Job Creation, $N e t \_J C_{t}$, is then given by summing the difference in job creation and job destruction over all groups of firms, i.e. $N e t_{-} J C_{t}=\Sigma_{g=1}^{G} N e t_{-} J C_{g t}$, where Net_J $J C_{g t}=J C_{g t}-J D_{g t}$. Finally, Job Reallocation is the sum of job creation and job destruction at time t, i.e. $J R_{t}=J C_{t}+J D_{t}$.

\subsection{Value added creation, value added destruction and net value added cre- ation}

Now we turn to productivity dynamics. Define labor productivity at time $t$ as $P_{t}=V A_{t} / E_{t}$, where $V A_{t}$ is total value added at time $t$ and $E_{t}$ is total employment at time $t . \quad P_{t}$ can be

\footnotetext{
${ }^{4}$ The number of firms in time $\mathrm{t}$ is the sum of firms staying in the market between $\mathrm{t}$ and $\mathrm{t}-1$ and firms entering in t, i.e. $n_{g t}=n_{g t}^{\text {Stay }}+n_{g t}^{\text {Entry }}$.

${ }^{5}$ The number of firms in time $\mathrm{t}-1$ is the sum of firms remaining in the market in $\mathrm{t}$ and those who exited at $\mathrm{t}-\mathrm{t}$, i.e. $n_{g t-1}=n_{g t}^{\text {Stay }}+n_{g t-1}^{E x i t}$.
} 
written as a weighted average of the labor productivity in each group, $P_{t}=\Sigma_{g=1}^{G} P_{g t} \times s_{g t}$, where $s_{g t}=E_{g t} / E_{t}$ is the employment share in group $g$ at time $t$ and $P_{g t}=\Sigma_{g=1}^{G} p_{i g t} \times s_{i g t}$ is the employment-weighted average productivity in group g where, $p_{i g t}=V A_{\text {igt }} / E_{\text {igt }}$ denotes firm-level productivity and $s_{i g t}=E_{i g t} / E_{g t}$ denotes a firm's within-group employment share.

By symmetry, $P_{t-1}=\Sigma_{g=1}^{G} P_{g t-1} \times s_{g t-1}$. The change in labor productivity between time $t$ and time $t-1, \Delta P_{t}$, can then be written as the sum of a within-group effect and between-group effect: ${ }^{6}$

$$
\Delta P_{t}=\underbrace{\sum_{g=1}^{G} \Delta P_{g t} \times \bar{s}_{g t}}_{\text {Within-group effect }}+\underbrace{\sum_{g=1}^{G}\left[\bar{P}_{g t}-\bar{P}_{t}\right] \times \Delta s_{g t}}_{\text {Between-group effect }}
$$

where $\bar{s}_{g t}=\frac{s_{g t}+s_{g t-1}}{2}, \bar{P}_{g t}=\frac{P_{g t}+P_{g t-1}}{2}$ and $\bar{P}_{t}=\frac{P_{t}+P_{t-1}}{2} .^{7}$

In Equation (3), $\Delta P_{g t}=P_{g t}-P_{g t-1}$ is the within-group change in labor productivity, and $\Delta s_{g t}=s_{g t}-s_{g t-1}$ is the change in the group shares. The within-group change in labor productivity, $\Delta P_{g t}$, can in turn be decomposed into a within-firm component, a between-firm component, a firm-entry component and a firm-exit component: ${ }^{8}$

$$
\begin{aligned}
& \Delta P_{g t}=\underbrace{\sum_{i=1}^{n_{g t}^{\text {Stay }}} \Delta p_{i g t} \times \bar{s}_{i g t}}_{\text {Within-firm effect }}+\underbrace{\sum_{i=1}^{n_{g t}^{\text {Stay }}} \Delta s_{i g t} \times\left[\bar{p}_{i g t}-\bar{P}_{g t}\right]}_{\text {Between-firm effect }}+ \\
& \underbrace{\sum_{i=1}^{n_{g t}^{\text {Entry }}} s_{i g t} \times\left[p_{i g t}-\bar{P}_{g t}\right]}_{\text {Firm-entry effect }}-\underbrace{\sum_{i=1}^{n_{g t-1}^{E x i t}} s_{i g t-1} \times\left[p_{i g t-1}-\bar{P}_{g t}\right]}_{\text {Firm-exit effect }} .
\end{aligned}
$$

where $\bar{s}_{i g t}=\frac{s_{i g t}+s_{i g t-1}}{2}, \bar{p}_{i g t}=\frac{p_{i g t}+p_{i g t-1}}{2}, \bar{P}_{g t}=\frac{P_{g t}+P_{g t-1}}{2}$. Moreover, $\Delta p_{i g t}=p_{i g t}-p_{i g t-1}$ and $\Delta s_{i g t}=s_{i g t}-s_{i g t-1}$ denote the firm-level changes in labor productivity and employment shares, respectively.

We are now ready to define value added creation (VC), value added destruction (VD) and

\footnotetext{
${ }^{6}$ See, Appendix A.2.1.

${ }^{7}$ This decomposition follows work by Jeon and Miller (2005) on their analysis of the US banking sector.

${ }^{8}$ This is the decomposition method proposed by Griliches and Regev (1995).
} 
net value added creation (Net_VC). From (3) and (4):

$$
\begin{aligned}
\Delta P_{t}= & N e t_{-} V C_{t}=\sum_{g=1}^{G} N e t_{-} V C_{g t}=\sum_{g=1}^{G} V C_{g t}-\sum_{g=1}^{G} V D_{g t}= \\
& \sum_{g=1}^{G} \underbrace{\left(V C_{g t}^{W i t h i n}+\left\{\left[\bar{P}_{g t}-\bar{P}_{t}\right] \times \Delta s_{g t} \mid\left[\bar{P}_{g t}-\bar{P}_{t}\right] \times \Delta s_{g t} \geq 0\right\}\right)}_{V C_{g t}}- \\
& \sum_{g=1}^{G} \underbrace{\left(V D_{g t}^{W i t h i n}-\left\{\left[\bar{P}_{g t}-\bar{P}_{t}\right] \times \Delta s_{g t} \mid\left[\bar{P}_{g t}-\bar{P}_{t}\right] \times \Delta s_{g t}<0\right\}\right)}_{V D_{g t}}
\end{aligned}
$$

Hence, the change in labor productivity $\Delta P_{t}$ simply equals net value creation, $N e t \_V C_{t}$, which, in turn, is the sum of net value added creation over all groups, $N e t_{-} V C_{g t}=V C_{g t}-V D_{g t}$. Hence, net value added creation at the group level is equal the difference between value added creation at the group level, $V C_{g t}$, and value added destruction at the group level, $V D_{g t}$ :

- Value added creation at the group level, $V C_{g t}$, is computed by first summing all positive terms in the within group change in productivity $\Delta P_{g t}$ in (4). This term, labelled $V C_{g t}^{W i t h i n}$, gives the increase in productivity from: (i) continuing firms which increase their productivity (the within-firm effect), (ii) expansion of firms with higher than average productivity (the between-firm effect), and (iii) net entry (i.e. the sum of the firm-entry and the firm-exit effects). Multiplying $V C_{g t}^{W i t h i n}$ with its weight $\bar{s}_{g t}$ from (3) and adding the between-group effect from (3), when this term is positive, gives the value added creation term $V C_{g t}$ in (5).

- Likewise, value added destruction at the group level, $N e t_{-} D C_{t}$, is computed by first summing all negative terms in the within group change in productivity $\Delta P_{g t}$ in (4). This term, labelled $V D_{g t}^{W i t h i n}$, gives the reduction in productivity from: (i) continuing firms which reduce their productivity (the within-firm effect), (ii) expansion of firms with lower than average productivity (the between-firm effect), and (iii) net entry (i.e. the sum of the firm-entry and the firm-exit effects). Multiplying $V D_{g t}^{W i t h i n}$ with its weight $\bar{s}_{g t}$ from (3) and adding the between-group effect from (3), when this term is negative, gives the value added destruction term $V D_{g t}$ in (5). 


\section{$3 \quad$ Job and productivity dynamics in Sweden}

\subsection{Data}

The empirical analysis requires us to be able to follow firms and individuals over time, which necessitates access to detailed data. We base our analysis on detailed register-based employeremployee data from Statistics Sweden (SCB) covering the period 1996-2013. ${ }^{9}$ The database includes firm, establishment, and individual data linked via unique identifiers and cover all private-sector firms.

To follow firms more reliably over time, we use additional data from Statistics Sweden (FAD data). These data make it possible to identify new firm entries and exits, which imply that we can analyse employment changes in (i) completely new units, (ii) continuing units and (iii) exiting units. ${ }^{10}$

As described above we use value added per employee as a measure of labor productivity. Value added is calculated as the output value minus the costs of purchased goods and services, excluding wages and other personnel costs (calculated by SCB according to the international definition). ${ }^{11}$

\subsection{The role of firm size}

We begin by examining job creation, job destruction and net job creation across four different firm-size classes over the entire time period (see Equation 1 and 2). ${ }^{12}$ Figure 1a depicts a negative relationship between firm size and the net employment change for the entire economy. While net job creation is largest for small and medium-sized firms, there is a much smaller net job creation for the largest firms. In terms of number of jobs, the results show that the smallest firms' share of total job reallocation (the sum of job creation and job destruction) is higher than their employment share. The opposite is true for job reallocation in the largest firms. Looking at sector differences, Figures $1 \mathrm{~b}$ and 1c show a much better development of net job creation for firms in the service sector than in the manufacturing sector. We also notice that net job creation is

\footnotetext{
${ }^{9}$ See, e.g., Davidson et al. (2014) and Hakkala et al. (2014) for recent articles based on the data.

${ }^{10}$ The use of organization numbers as a method of identifying continuing, entering and exiting firms can be problematic because these numbers can change. See Andersson and Arvidsson (2011) for details on the FAD data.

${ }^{11}$ Value added per employee is a commonly used measure of productivity and is easily comparable across countries. Another measure of productivity is Total Factor Productivity (TFP). Studies that use both labor productivity and TFP typically find similar results irrespective of the measure used (see, for instance Bartelsman and Doms (2000) and Syverson (2011) for discussions of different productivity concepts). Note that we use aggregate consumer price deflators so price changes may reflect changes in mark-ups. In particular, it might be that firms with different size and age may be active in industries where the mark-ups have changed differently over time. Unfortunately we do not have accesses to price deflators at the industry level.

${ }^{12}$ These calculations are based on firms with at least 10 employees.
} 
negative for the largest firms in the manufacturing sector during the period 1996-2013. Overall, the basic job flows results in Figure 1 suggest large differences in job dynamics across firms of different sizes and industries.

To examine how firm-size differences are related to productivity, Figure 2 depicts the contribution of total labor productivity for each firm-size group over the period 1996-2013 using calculations described in Section 2.2.

From Equation 3, the overall productivity change $\left(\Delta P_{t}\right)$ can be decomposed into a within-size group and a between-size group component. Figure 2a shows that the within-size group effect is much larger than the corresponding between-size group effect. The largest part originates from the within component for the largest firm size group (firms with at least 500 employees). To further exploit the important within-size group effect we continue in Figure $2 \mathrm{~b}$ and show the decomposition of productivity within size groups described by Equation $4\left(\Delta P_{g t}\right)$. For all size classes, the within-firm effect dominates with the strongest contribution stemming from the largest firms. Also within firm size groups we have that the between effect is very small. Finally, in Figures 2c-e we present evidence on value added creation, value added destruction and net productivity change for each size group (Equation 5). For the entire economy, the total increase in value added per employee (i.e. net value added creation), over the period is about 160,000 SEK (Figure 2c). This is the sum of net value added creation for each firm size class over the entire period. It is also by construction equal to the sum of the within-size group and between-size group components depicted in Figure 2a.

The largest firms (with at least 500 employees) account for nearly 80,000 SEK of the total increase in net value added creation for firms with at least 10 employees. Thus, the largest firms created around half of the increase in value added per employee for the period we study. Figure $2 \mathrm{c}$ also shows that, for the entire economy, the overall dynamics of value added is far greater than the corresponding net changes for each group. Behind an increase in net value added creation of around 80,000 SEK per employee for the largest firms, there are more than 900,000 SEK per employee in overall value added reallocation (i.e. the sum of created and destroyed value added, $V R=V C+V D)$. This implies a high degree of heterogeneity in terms of productivity for the largest firms. While some firms have had a very positive development, others have experienced a negative productivity growth during the period. This heterogeneity in the form of a substantial overall value added reallocation $(V R)$ of created and destroyed value added can also be seen in the other size groups, although the magnitudes are smaller.

We also note that there are considerable differences in productivity dynamics between sectors. Large firms accounts for most of the productivity dynamics in the manufacturing sector, while 
in the service sector value reallocation is much more evenly distributed across different firm size groups (see Figures $2 \mathrm{~d}$ and 2e).

Comparing Figures 1 and 2, we see that while large firms accounted for the largest share of net value added creation, the largest firms also constituted the group with the fewest new net jobs created during the period. This dichotomy between employment growth in small firms and productivity growth in large firms is most pronounced in the manufacturing sector.

\subsection{Firm age}

Haltiwanger et al. (2013) analyze how the relationship between firm size and net employment growth is affected by firm age. ${ }^{13}$ They find an inverse relationship between firm size and net job growth. However, when controlling for firm age, Haltiwanger et al. (2013) find that the relationship between firm size and job growth disappears. In our data, we know if a firm was active before 1986 but not earlier. Then, we define age from this cut-off and construct five age groups. 14

Before presenting results where we show the combined influence of firm size and age, we first briefly discuss results on firm age and job and productivity dynamics. Very similar to the results for firm size above, we notice that net value added creation (incraese in productivity) is highest in the oldest firms (Figure 4), whereas this group of firms experienced a much worse development of net job creation as compared to the youngest firms (Figure 3).

\subsection{Firm age and firm size}

Figure 5 explores net job creation and value added creation for both firm size and firm age. Figure 5a shows the net change in employment for all possible combinations of size and age of firms. Figure $5 \mathrm{~b}$ depicts the net change in value creation in terms of value added per employee. Young, small firms are located in the south-west corner, while large, old firms are located in the north-east corner. Medium size- and medium age firms can be found in the middle of the diagram.

While Figure 5a reveals that hardly any net employment is created in the oldest firms, Figure $5 \mathrm{~b}$ shows that most of the value added creation occurs in these mature firms, with the greatest

\footnotetext{
${ }^{13}$ This result is consistent with e.g. Neumark et al. (2011) who present evidence that small firms contribute disproportionally to net employment growth. See also Anyadike-Danes et al. (2015) who use cross-country data and find that adding controls for age causes the relationship between firms size and job growth to disappear.

14 "Young firms" consists of groups of firms which are 0-1 year and 2-3 years, where the former group consists of start-ups. "Medium age" firms are firms aged 4-9 years. "Old firms" are firms aged 10-13 years and firms which are older than 14 years Given the structure of the firm age data, our calculations on firm age starts in the year 2000 (results are not qualitatively affected by this).
} 
increase for the largest firms which contains large Swedish multinational firms.

Summing up our result on job creation in the Swedish business sector gives a similar picture as Haltiwanger et al. (2013) study on the U.S. business sector. It is age and not size which is the important characteristic for job creation: start-ups and young businesses create the large bulk of new jobs. Our examination of the Swedish productivity dynamics shows that old and large firms are behind the major part of the increase in productivity during the period we study.

\subsection{The role of education}

It is likely that small new firms and large established firms specialized in different activities during the industrial restructuring process under study. For instance, large incumbent firms may have reduced their employment of less skilled labor while improving their productivity by upgrading their technology and increasing their employment of skilled labor.

To investigate these issues, we group employees into three different education categories. ${ }^{15}$ Figure 6 shows net job creation separated by educational level and firm size and age, thus taking into account job heterogeneity. ${ }^{16}$ A number of interesting observations emerge from the figure.

First, jobs with low-educated employees only increase in start-ups (see Figure 6a). All other firm-age groups reduce the number of employees with only compulsory education, with the largest decline in the oldest firms. Another notable feature in Figure 6a is that job destruction of employees with compulsory education is concentrated in the large established (oldest) firms. The pattern for individuals with secondary education in Figure 6b is broadly similar, again with the exception that the oldest and largest firms only display small changes employment with secondary education, in sharp contrast to the massive reduction of employees with only compulsory education.

Looking at Figure 6c, net job creation for individuals with post-secondary education in startups partly declines with firm size, whereas net job creation for individuals with post-secondary education in the oldest firms increases with size.

Our results indicate that large established firms experienced an increasing trend in the overall educational level of their workforce. These firms hired more highly educated employees while simultaneously reducing the number of workers with primarily compulsory education. Increased opportunities for outsourcing and the use of ICT in combination with skill-biased technological

\footnotetext{
${ }^{15}$ These are (1) workers with at most 9 years of elementary education, (2) workers with 1-2 years of upper secondary education and (3) workers with at least 3 years of post-secondary education.

${ }^{16}$ This separation of job flows across educational attainment is uncommon in the job dynamics literature, where essentially all the evidence concerns the total number of jobs and does not distinguish between the types of jobs that are created and destroyed. One exception is Gartell et al. (2010). See also Heyman, Norbäck and Persson (2016) for an analysis on start-ups and employment dynamics.
} 
change did likely facilitate large firms' efforts to concentrate on their core production activities and outsource their other activities to small and medium-sized firms.

\section{Conclusions}

We have examined the job and productivity creation in the Swedish business sector during the 1990s and 2000s. Our paper contributes to the literature on job and productivity dynamics by using a novel implementation of the so-called Davis et al. methodology on gross job flows to analyze both job and productivity dynamics in a consistent way. We have applied the similar method that has been extensively used to analyze the effect of job creation and job destruction on productivity dynamics. Our framework is also closely related to the literature that decompose overall productivity into different sub-components.

We find that small and large firms have played different roles. Small firms have created most of the new net jobs, in particular for low and medium educated employees. Small firms have also contributed to the increase in productivity in the service sector. Large firms in the manufacturing sector are by far the largest contributor to net value added creation.

When also accounting for firm age, we find that the job creation process in Sweden looks similar to the one in the US: it is young firms that are most important for net job creation. However, our examination of the productivity dynamics shows that both age and size matters: we find that it is old, large firms that generate most of the increase in productivity.

An interesting avenue for future research would be to employ the methodology used in this paper to study the recent slow-down in aggregate productivity growth - as well as the increased dispersion of productivity growth - and the potential association with the increased pace of the ICT driven automatization process.

\section{References}

[1] Andersson, J. and G. Arvidson (2011). 'Företagens och arbetsställenas dynamik (FAD)', Statistics Sweden Working manuscript.

[2] Anyadike-Danes, M., Bjuggren, C.-M., Gottschalk, S., Hölzl, W., Johansson, D., Maliranta, M., and Myrann, A. (2015). "An international cohort comparison of size effects on job growth", Small Business Economics, 44(4), 821-844.

[3] Bartelsman, E. J. and M. Doms (2000). 'Understanding productivity: lessons from longitudinal microdata', Journal of Economic Literature, 38(3), 569-594. 
[4] Davidson, C., F. Heyman, S. Matusz, F. Sjöholm and S. Chun Zhu (2014). 'Globalization and imperfect labor market sorting', Journal of International Economics, 94(2), 177-194.

[5] Davis, S. J., J. Haltiwanger, and S. Schuh (1997). Job Creation and Destruction. Cambridge, MA: MIT Press.

[6] Foster, L., J. Haltiwanger and C. J. Krizan (2001). 'Aggregate productivity growth. Lessons from microeconomic evidence', in C. R. Hulten, E. R. Dean, and M. J. Harper (eds.), New developments in productivity analysis,' University of Chicago Press, Chicago.

[7] Gartell, M., A. C. Jans, and H. Persson (2010). 'The importance of education for the reallocation of labour: evidence from Swedish linked employer-employee data 1986-2002', Labour Economics,17(1), 206-214.

[8] Griliches, Z. and H. Regev (1995). 'Firm productivity in Israeli industry 1979-1988', Journal of Econometrics, 65(1), 175-203.

[9] Jeon, Y. and S.M. Miller (2005). 'An 'Ideal" Decomposition of Industry Dynamics: An application to the Natinwide and State Level U.S. Banking Industry', Univeristy of Connecticut WP 200525.

[10] Neumark, D., B. Wall, and J. Zhang (2011). 'Do Small Businesses Create More Jobs? New Evidence for the United States from the National Establishment Time Series, Review of Economics and Statistics, 93(1) (2011), 16-29.

[11] Hakkala, K., F. Heyman and F. Sjöholm (2014). 'Multinational firms and job tasks', European Economic Review, 66, 248-265.

[12] Haltiwanger, J., R. Jarmin and J. Miranda (2013). 'Who Creates Jobs? Small Versus Large Versus Young', Review of Economics and Statistics, 95(2),347-361.

[13] Heyman, F., P.-J. Norbäck and L. Persson (2016). "When the Swedish Business Sector Became More Entrepreneurial than the U.S. and Why", IFN Working Paper No. 1147, Research Institute of Industrial Economics.

[14] OECD (2013). OECD compendium of productivity indicators 2013, OECD Publishing.

[15] Syverson, C. (2011). 'What determines productivity?', Journal of Economic Literature 49(2), $326-365$. 


\section{A Appendix:}

\section{A.1 Employment dynamics}

There are $\{1,2,3, \ldots, g, \ldots, G\}$ groups of firms and $\{1,2,3, \ldots, t, \ldots, T\}$ time periods. Let $n_{g t}$ denote the number of firms in group $g$ at time $t$. Let $E_{i g t}$ be the number of employees in firm $i$ in group $g$ at time $t$, and let $E_{i g t-1}$ be the employment in this firm in time $t-1$. Then, the change in the number of jobs in firm $i$ between $t$ and $t-1, \Delta E_{i t}$, is:

$$
\Delta E_{i g t}=E_{i g t}-E_{i g t-1}
$$

Job creation in Firm $i$ in time $t, J C_{i g t}$, and job destruction in firm $i$ in time $t, J D_{i g t}$, are defined as

$$
\begin{aligned}
& J C_{i g t}=\left\{\begin{array}{c}
\Delta E_{i g t} \mid \Delta E_{i g t} \geq 0 \\
E_{i g t} \mid E_{i g t-1}=0,
\end{array}\right. \\
& J D_{i g t}=\left\{\begin{array}{c}
-\Delta E_{i g t} \mid \Delta E_{i g t}<0, \\
E_{i g t-1} \mid E_{i g t}=0 .
\end{array}\right.
\end{aligned}
$$

Thus, firms can be separated into "Stayers" or continuers which consists out of firms which are present both in time $t$ and $t-1$, "Entrants" which are firms which enter into the market at time $t$ and "Exiters", which exit the market at time $t-1$. The number of firms of different types within each group $g$ in time $t$ fulfill:

$$
\begin{aligned}
n_{g t} & =n_{g t}^{\text {Stay }}+n_{g t}^{\text {Entry }}, \\
n_{g t-1} & =n_{g t}^{\text {Stay }}+n_{g t-1}^{\text {Exit }},
\end{aligned}
$$

where we note that $\sum_{g=1}^{G} n_{g t}=n_{t}$ and $\sum_{g=1}^{G} n_{g t-1}=n_{t-1}$. 


\section{A.1.1 Job creation}

Making use of (A.2) and (A.4), overall job creation in time $t$ can be written as

$$
\begin{aligned}
J C_{t} & =\sum_{g=1}^{G} \underbrace{\left(\sum_{i=1}^{n_{g t}^{\text {Stay }}}\left[\Delta E_{i g t} \mid \Delta E_{i g t} \geq 0\right]+\sum_{i=1}^{n_{g t}^{\text {Entry }}} E_{i g t}\right)}_{J C_{g t}: \text { job creation in group } g \text { at time } t} \\
& =\sum_{g=1}^{G} J C_{g t}
\end{aligned}
$$

\section{A.1.2 Job destruction}

Making use of (A.3) and (A.5), overall job destruction in time $t$ can be written

$$
\begin{aligned}
J D_{t} & =\sum_{g=1}^{G} \underbrace{\left(\sum_{i=1}^{n_{g t}^{\text {Stay }}}\left[-\Delta E_{i g t} \mid \Delta E_{i g t}<0\right]+\sum_{i=1}^{n_{g x-1}^{E x i t}} E_{i g t-1}\right)}_{J D_{g t}: \text { job destruction in group } g \text { at time } t} \\
& =\sum_{g=1}^{G} J D_{g t}
\end{aligned}
$$

\section{A.1.3 Net job creation in time $t$}

Using (A.7) and (A.9) we can now write aggregate net job creation as

$$
\begin{aligned}
\text { Net_JCt } & =J C_{t}-J D_{t} \\
& =\sum_{g=1}^{G} J C_{g t}-\sum_{g=1}^{G} J D_{g t} \\
& =\sum_{g=1}^{G} \underbrace{\left[J C_{g t}-J D_{g t}\right]}_{\text {Net_JCgt }} \\
& =\sum_{g=1}^{G} N e t_{-} J C_{g t}
\end{aligned}
$$




\section{A.1.4 Net job creation, job creation and job destruction}

We can now show how the different groups of firms contribute to net job creation, job creation and job destruction over time.

$$
\begin{aligned}
\text { Net_JC } & =\sum_{t=1}^{T} N e t_{-} J C_{t} \\
& =\underbrace{\sum_{t=1}^{T} J C_{t}}_{J C}-\underbrace{\sum_{t=1}^{T} J D_{t}}_{J D}
\end{aligned}
$$

where $N e t \_J C$ is the total net job creation across all groups and time periods, $J C$ is the total job creation across all groups and time periods and $J D$ is the total job destruction across all groups and time periods. "). The sum of total job creation and total job destruction is equal to total job reallocation $(J R)$.

\section{A.2 Productivity dynamics}

Let $V A_{\text {igt }}$ be the value added in firm $i$ which belongs to group $g$ at time $t$. Then, let $V A_{t}$ be the total value added at time $t$, and let $E_{t}$ be the total number of employees at time $t$.

$$
\begin{aligned}
V A_{t} & =\sum_{g=1}^{G}\left(\sum_{i=1}^{n_{g t}} V A_{i g t}\right) \\
E_{t} & =\sum_{g=1}^{G}\left(\sum_{i=1}^{n_{g t}} E_{i g t}\right)
\end{aligned}
$$

Using (A.14) and (A.15), we can rewrite total value added per employee at time $t, P_{t}$, as 
follows

$$
\begin{aligned}
& P_{t}=\frac{V A_{t}}{E_{t}}, \\
& =\frac{\sum_{g=1}^{G}\left(\sum_{i=1}^{n_{g t}} V A_{i g t}\right)}{\sum_{g=1}^{G}\left(\sum_{i=1}^{n_{g t}} E_{i g t}\right)} \\
& =\sum_{g=1}^{G}\left(\frac{\sum_{i=1}^{n_{g t}} V A_{i g t}}{\sum_{g=1}^{G}\left[\sum_{i=1}^{n_{g t}} E_{i g t}\right]}\right) \text {, } \\
& =\sum_{g=1}^{G}\left(\frac{\left(\sum_{i=1}^{n_{g t}} V A_{i g t}\right) \times\left(\sum_{i=1}^{n_{g t}} E_{i g t}\right)}{\left(\sum_{i=1}^{n_{g t}} E_{i g t}\right) \times \sum_{g=1}^{G}\left[\sum_{i=1}^{n_{g t}} E_{i g t}\right]}\right) \text {, } \\
& =\sum_{g=1}^{G}\left(\frac{\left(\sum_{i=1}^{n_{g t}} \frac{V A_{i g t}}{E_{i g t}} \times E_{i g t}\right) \times\left(\sum_{i=1}^{n_{g t}} E_{i g t}\right)}{\left(\sum_{i=1}^{n_{g t}} E_{i g t}\right) \times \sum_{g=1}^{G}\left[\sum_{i=1}^{n_{g t}} E_{i g t}\right]}\right), \\
& =\sum_{g=1}^{G}\left(\frac{\left(\sum_{i=1}^{n_{g t}} \frac{V A_{i g t}}{E_{i g t}} \times E_{i g t}\right)}{\left(\sum_{i=1}^{n_{g t}} E_{i g t}\right)} \times \frac{\left(\sum_{i=1}^{n_{g t}} E_{i g t}\right)}{\sum_{g=1}^{G}\left[\sum_{i=1}^{n_{g t}} E_{i g t}\right]}\right) \text {, } \\
& =\sum_{g=1}^{G}\left(\left(\sum_{i=1}^{n_{g t}} \frac{V A_{i g t}}{E_{i g t}} \times \frac{E_{i g t}}{\left(\sum_{i=1}^{n_{g t}} E_{i g t}\right)}\right) \times \frac{\left(\sum_{i=1}^{n_{g t}} E_{i g t}\right)}{\sum_{g=1}^{G}\left[\sum_{i=1}^{n_{g t}} E_{i g t}\right]}\right) .
\end{aligned}
$$

To proceed, define $p_{i g t}$ as the value added per employee in firm $i$ in group $g$ at time $t$. Let $s_{i g t}$ be the share of total employment in group $g$ at time $t$ allocated to firm $i$. Finally, let $s_{g t}$ be 
the share of workers in group $g$ out of total employment at time $t$.

$$
\begin{aligned}
p_{i g t}= & \frac{V A_{i g t}}{E_{i g t}} \\
s_{i g t}= & \frac{E_{i g t}}{\sum_{i=1}^{n_{g t}} E_{i g t}} \\
s_{g t}= & \frac{\sum_{i=1}^{n_{g t}} E_{i g t}}{\sum_{g=1}^{G}\left[\sum_{i=1}^{n_{g t}} E_{i g t}\right]}
\end{aligned}
$$

Using (A.17)-(A.19), expression (A.16) can after manipulation be written as

$$
P_{t}=\sum_{g=1}^{G}\left(\sum_{i=1}^{n_{g t}} p_{i g t} \times s_{i g t}\right) \times s_{g t} .
$$

The term within brackets in (A.20) is the employment-weighted productivity in group $g$ at time $t$

$$
P_{g t}=\sum_{i=1}^{n_{g t}} p_{i g t} \times s_{i g t} .
$$

Using (A.21) in (A.20) we have shown that the aggregate productivity can be written as the employment weighted average productivity where the weights consists out of the weights each group has in each time t:

$$
P_{t}=\sum_{g=1}^{G} P_{g t} \times s_{g t} .
$$

\section{A.2.1 Decomposing the change in productivity (Jeon and Miller, 2005)}

By symmetry with (A.22), employment weighted average productivity at time $t-1$ is

$$
P_{t-1}=\sum_{g=1}^{G} P_{g t-1} \times s_{g t-1},
$$

where

$$
P_{g t-1}=\sum_{i=1}^{n_{g t-1}} p_{i g t-1} \times s_{i g t-1} .
$$

From (A.22) and (A.23), the change in employment weighted productivity at time $t, \Delta P_{t}$, is 


$$
\Delta P_{t}=P_{t}-P_{t-1}=\sum_{g=1}^{G} P_{g t} \times s_{g t}-\sum_{g=1}^{G} P_{g t-1} \times s_{g t-1}
$$

In a first step, rewrite (A.25) as follows

$$
\begin{aligned}
& \Delta P_{t}=\sum_{g=1}^{G} P_{g t} \times s_{g t}-\sum_{g=1}^{G} P_{g t-1} \times s_{g t-1} \\
& +\underbrace{\left(\sum_{g=1}^{G} P_{g t} \times s_{g t-1}-\sum_{g=1}^{G} P_{g t} \times s_{g t-1}\right)}_{=0} \\
& +\underbrace{P_{t} \overbrace{\left(\sum_{g=1}^{G} s_{g t-1}\right)}^{=1}-P_{t} \overbrace{\left(\sum_{g=1}^{G} s_{g t}\right)}^{=1}}_{=0} .
\end{aligned}
$$

Simplifying (A.26) leads to:

$$
\Delta P_{t}=\sum_{g=1}^{G}\left[P_{g t}-P_{t}\right] \times s_{g t}+\sum_{g=1}^{G}\left[P_{g t}-P_{g t-1}\right] \times s_{g t-1}-\sum_{g=1}^{G}\left[P_{g t}-P_{t}\right] \times s_{g t-1}
$$

Define $\Delta P_{g t}$ as the change in the average productivity between $t$ an $t-1$ within each group $g$, and $\Delta s_{g t}$ as the change between time $t$ and time $t-1$ in the share of workers allocated to group $g$

$$
\begin{aligned}
\Delta P_{g t} & =P_{g t}-P_{g t-1}, \\
\Delta s_{g t} & =s_{g t}-s_{g t-1} .
\end{aligned}
$$

Using (A.28) and (A.29), we can write (A.27) as follows

$$
\Delta P_{t}=\sum_{g=1}^{G} \Delta P_{g t} \times s_{g t-1}+\sum_{g=1}^{G}\left[P_{g t}-P_{t}\right] \times \Delta s_{g t}
$$

As a second step, rewrite (A.25) as follows: 


$$
\begin{aligned}
\Delta P_{t}= & \sum_{g=1}^{G} P_{g t} \times s_{g t}-\sum_{g=1}^{G} P_{g t-1} \times s_{g t-1} \\
& \underbrace{+\left(\sum_{g=1}^{G} P_{g t-1} \times s_{g t}-\sum_{g=1}^{G} P_{g t-1} \times s_{g t}\right)}_{=0} \\
& \underbrace{+\overbrace{t-1}^{\left(\sum_{g=1}^{G} s_{g t-1}\right)}-P_{t-1} \overbrace{\left(\sum_{g=1}^{G} s_{g t}\right)}^{=1}}_{=0} .
\end{aligned}
$$

Simplifying (A.31) and using (A.28) and (A.29), we get

$$
\Delta P_{t}=\sum_{g=1}^{G} \Delta P_{g t} \times s_{g t}+\sum_{g=1}^{G}\left[P_{g t-1}-P_{t-1}\right] \times \Delta s_{g t}
$$

In a third step, adding (A.30) and (A.32) gives the following relationship:

$$
2 \Delta P_{t}=\sum_{g=1}^{G} \Delta P_{g t} \times\left(s_{g t}+s_{g t-1}\right)+\sum_{g=1}^{G}\left[\left(P_{g t}+P_{g t-1}\right)-\left(P_{t}+P_{t-1}\right)\right] \times \Delta s_{g t}
$$

From (A.33), we can then solve solve for $\Delta P_{t}$ :

$$
\Delta P_{t}=\underbrace{\sum_{g=1}^{G} \Delta P_{g t} \times \bar{s}_{g t}}_{\text {Within-group effect }}+\underbrace{\sum_{g=1}^{G}\left[\bar{P}_{g t}-\bar{P}_{t}\right] \times \Delta s_{g t}}_{\text {Between-group effect }}
$$

where $\bar{s}_{g t}=\frac{s_{g t}+s_{g t-1}}{2}, \bar{P}_{g t}=\frac{P_{g t}+P_{g t-1}}{2}$ and $\bar{P}_{t}=\frac{P_{t}+P_{t-1}}{2}$.

Hence, from (A.34) the change in labor productivity, $\Delta P_{t}$, can be written as the sum of a within-size group effect, which mirrors the impact of changing productivity within groups, and and a between-size group effect, which mirrors changing shares of employment between groups.

\section{A.2.2 Decomposing the within group effect (Griliches and Regev, 1995)}

To further explore the change in productivity, we can apply the decomposition method proposed by Griliches and Regev (1995) to the within group change in productivity $\Delta P_{g t}$ (see also Foster 
et. al, (2001) for details).

Using (A.4) and (A.5), the change in within group productivity, $\Delta P_{g t}$, can be rewritten as follows:

$$
\begin{aligned}
\Delta P_{g t} & =P_{g t}-P_{g t-1} \\
& =\sum_{i=1}^{n_{g t}} p_{i g t} \times s_{i g t}-\sum_{i=1}^{n_{g t-1}} p_{i g t-1} \times s_{i g t-1} \\
& =\sum_{i=1}^{n_{g t}^{\text {Stay }}} p_{i g t} \times s_{i g t}+\sum_{i=1}^{n_{g t}^{\text {ntry }}} p_{i g t} \times s_{i g t}-\sum_{i=1}^{n_{g t}^{\text {Stay }}} p_{\text {igt }-1} \times s_{i g t-1}-\sum_{i=1}^{n_{g t-1}^{E x i t}} p_{i g t-1} \times s_{i g t}(\mathrm{~A}
\end{aligned}
$$

In the first step, rewrite (A.35) as follows

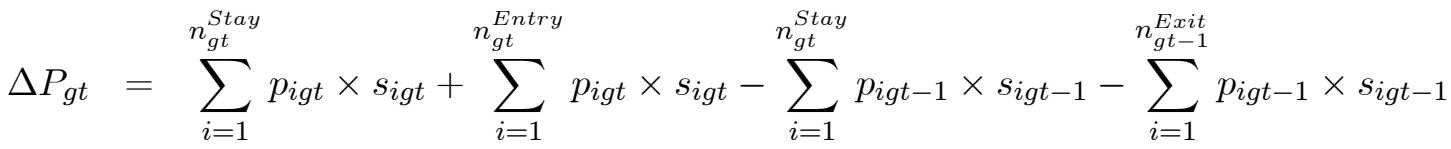

$$
\begin{aligned}
& +\underbrace{\left(\sum_{i=1}^{n_{g t}^{\text {Stay }}} p_{i g t} \times s_{i g t-1}-\sum_{i=1}^{n_{g t}^{\text {Stay }}} p_{i g t} \times s_{i g t-1}\right)}_{=0}
\end{aligned}
$$

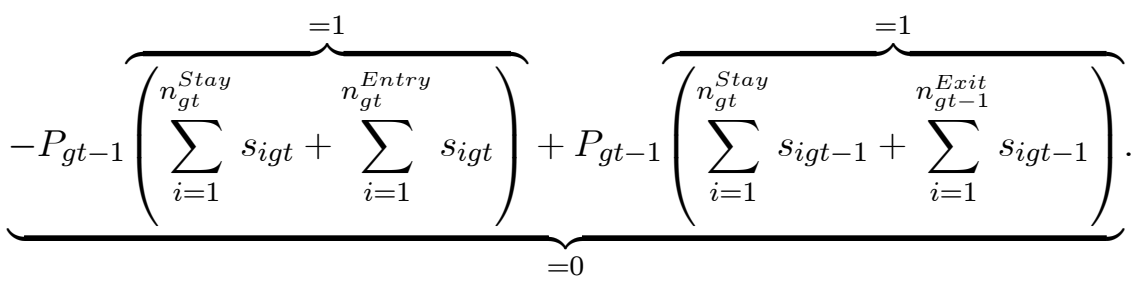

Simplifying (A.36), and using $\Delta p_{i g t}=p_{i g t}-p_{i g t-1}$ and $\Delta s_{i g t}=s_{i g t}-s_{i g t-1}$, the change in within group productivity can be written:

$$
\begin{aligned}
\Delta P_{g t}= & \sum_{i=1}^{n_{g t}^{\text {Stay }}}\left(p_{i g t}-P_{g t-1}\right) \times \Delta s_{i g t}+\sum_{i=1}^{n_{g t}^{\text {Stay }}} \Delta p_{\text {igt }} \times s_{i g t-1} \\
& +\sum_{i=1}^{n_{g t}^{\text {Entry }}}\left(p_{i g t}-P_{g t-1}\right) \times s_{i g t}-\sum_{i=1}^{n_{g t-1}^{E x i t}}\left(p_{i g t-1}-P_{g t-1}\right) \times s_{i g t-1}
\end{aligned}
$$


In the second step, now rewrite (A.35) as follows

$$
\begin{aligned}
& \Delta P_{g t}=\sum_{i=1}^{\substack{\text { Stay } \\
n_{t}}} p_{i g t} \times s_{i g t}+\sum_{i=1}^{n_{g t}^{\text {Entry }}} p_{\text {igt }} \times s_{i g t}-\sum_{i=1}^{n_{g t}^{\text {Stay }}} p_{i g t-1} \times s_{i g t-1}-\sum_{i=1}^{n_{g x t-1}^{E x i t}} p_{i g t-1} \times s_{i g t-1} \\
& \underbrace{\left(\sum_{i=1}^{n_{g t}^{\text {Stay }}} p_{i g t-1} \times s_{i g t}-\sum_{i=1}^{n_{g t}^{\text {Stay }}} p_{\text {igt-1 }} \times s_{\text {igt }}\right)}_{=0} \\
& \underbrace{-P_{g t} \overbrace{\left(\sum_{i=1}^{n_{g t}^{\text {Stay }}} s_{i g t}+\sum_{i=1}^{n_{g t}^{\text {Entry }}} s_{i g t}\right)}^{=1}+P_{g t} \overbrace{\left(\sum_{i=1}^{n_{g t}^{\text {Stay }}} s_{i g t-1}+\sum_{i=1}^{n_{g t-1}^{\text {Exit }}} s_{i g t-1}\right)}^{=1} .}_{=0}
\end{aligned}
$$

Simplifying (A.38), and using $\Delta p_{i g t}=p_{i g t}-p_{i g t-1}$ and $\Delta s_{i g t}=s_{i g t}-s_{i g t-1}$, the change in within group productivity can now be written:

$$
\begin{aligned}
\Delta P_{g t}= & \sum_{i=1}^{n_{g t}^{\text {Stay }}}\left(p_{i g t-1}-P_{g t}\right) \times \Delta s_{i g t}+\sum_{i=1}^{n_{g t}^{\text {Stay }}} \Delta p_{\text {igt }} \times s_{i g t} \\
& +\sum_{i=1}^{n_{g t}^{\text {Entry }}}\left(p_{i g t}-P_{g t}\right) \times s_{i g t}-\sum_{i=1}^{n_{g t-1}^{E x i t}}\left(p_{i g t-1}-P_{g t}\right) \times s_{i g t-1}
\end{aligned}
$$

In the third step, add (A.37) and (A.39) to get: 


$$
\begin{aligned}
& 2 \Delta P_{g t}=\sum_{i=1}^{\substack{\text { Stay } \\
g t}}\left(p_{i g t-1}-P_{g t}\right) \times \Delta s_{i g t}+\sum_{i=1}^{n_{g t}^{\text {Stay }}} \Delta p_{i g t} \times s_{i g t} \\
& +\sum_{i=1}^{\substack{\text { Entry } \\
g t}}\left(p_{i g t}-P_{g t}\right) \times s_{i g t}-\sum_{i=1}^{n_{g t-1}^{E x i t}}\left(p_{i g t-1}-P_{g t}\right) \times s_{i g t-1} \\
& +\sum_{i=1}^{\substack{\text { Staay } \\
g t}}\left(p_{i g t}-P_{g t-1}\right) \times \Delta s_{i g t}+\sum_{i=1}^{n_{g t}^{\text {Stay }}} \Delta p_{i g t} \times s_{i g t-1} \\
& +\sum_{i=1}^{n_{g t}^{\text {Entry }}}\left(p_{i g t}-P_{g t-1}\right) \times s_{i g t}-\sum_{i=1}^{n_{g t-1}^{E x i t}}\left(p_{i g t-1}-P_{g t-1}\right) \times s_{i g t-1}
\end{aligned}
$$

Solving for $\Delta P$ in (A.40), we obtain:

$$
\begin{aligned}
& \Delta P_{g t}=\underbrace{\sum_{i=1}^{n_{g t}^{\text {Stay }}} \Delta p_{i g t} \times \bar{s}_{i g t}}_{\text {Within-firm effect }}+\underbrace{\sum_{i=1}^{n_{g t}^{\text {Stay }}} \Delta s_{i g t} \times\left[\bar{p}_{i g t}-\bar{P}_{g t}\right]}_{\text {Between-firm effect }}+ \\
& \underbrace{\sum_{i=1}^{n_{g t}^{\text {Entry }}} s_{i g t} \times\left[p_{i g t}-\bar{P}_{g t}\right]}_{\text {Firm-entry effect }}-\underbrace{\sum_{i=1}^{n_{g t-1}^{E x i t}} s_{i g t-1} \times\left[p_{i g t-1}-\bar{P}_{g t}\right]}_{\text {Firm-exit effect }} .
\end{aligned}
$$

where $\bar{s}_{i g t}=\frac{s_{i g t}+s_{i g t-1}}{2}, \bar{p}_{i g t}=\frac{p_{i g t}+p_{i g t-1}}{2}$ and $\bar{P}_{g t}=\frac{P_{g t}+P_{g t-1}}{2}$.

Thus, from (A.41) the change in productivity in group $g$ at time $t, \Delta P_{g t}$, can be written as the sum of a within-firm effect, a between-firm effect, a firm-entry effect and a firm exit effect

\section{A.2.3 Value Added Creation (VC) and Value Added Destruction (VD)}

We have previously defined job creation and job destruction. Let us now define value added creation and value added destruction. We start by decomposing the "within group" term in (A.34), $\Delta P_{g t}$, into a value creation term and a value destruction term

$$
\Delta P_{g t}=V C_{g t}^{W}-V D_{g t}^{W}
$$

Value added creation for group $g$ at time $t, V C_{t}^{W}$, is simply derived from summing the positive 
terms in (A.41):

$$
\begin{aligned}
& V C_{g t}^{W}=\underbrace{\sum_{i=1}^{n_{g t}^{\text {Stay }}}\left\{\Delta p_{i g t} \times \bar{s}_{i g t} \mid \Delta p_{i g t} \times \bar{s}_{i g t} \geq 0\right\}}_{\text {Within-firm effect }}+ \\
& \underbrace{\sum_{i=1}^{n_{g t}^{\text {Stay }}}\left\{\Delta s_{i g t} \times\left[\bar{p}_{i g t}-\bar{P}_{g t}\right] \mid \Delta s_{i g t} \times\left[\bar{p}_{i g t}-\bar{P}_{g t}\right] \geq 0\right\}}_{\text {Between-firm effect }}+ \\
& \underbrace{\sum_{i=1}^{n_{g t}^{\text {Entry }}}\left\{s_{i g t} \times\left[p_{i g t}-\bar{P}_{g t}\right] \mid s_{i g t} \times\left[p_{i g t}-\bar{P}_{g t}\right] \geq 0\right\}}_{\text {Entry effect }} \\
& -\underbrace{\sum_{i=1}^{n_{g t}^{E n t r y}}\left\{s_{i g t-1} \times\left[p_{i g t-1}-\bar{P}_{g t}\right] \mid s_{i g t-1} \times\left[p_{i g t-1}-\bar{P}_{g t}\right] \leq 0\right\}}_{\text {Exit effect }} .
\end{aligned}
$$

Value added destruction for group $g$ at time $t, V D_{t}^{W}$, is derived by simply summing the strictly negative terms in (A.41)) and adjusting so that the sum is positive:

$$
\begin{aligned}
& V D_{g t}^{W}=-\underbrace{\sum_{i=1}^{n_{t}^{\text {Stay }}}\left\{\Delta p_{i g t} \times \bar{s}_{i g t} \mid \Delta p_{i g t} \times \bar{s}_{i g t}<0\right\}}_{\text {Within-firm effect }}+ \\
& -\underbrace{\sum_{i=1}^{n_{g t}^{\text {Stay }}}\left\{\Delta s_{i g t} \times\left[\bar{p}_{i g t}-\bar{P}_{g t}\right] \mid \Delta s_{i g t} \times\left[\bar{p}_{i g t}-\bar{P}_{g t}\right]<0\right\}}_{\text {Between-firm effect }}+ \\
& -\underbrace{\sum_{i=1}^{n_{g t}^{\text {Entry }}}\left\{s_{i g t} \times\left[p_{i g t}-\bar{P}_{g t}\right] \mid s_{i g t} \times\left[p_{i g t}-\bar{P}_{g t}\right]<0\right\}}_{\text {Entry effect }}+ \\
& \underbrace{\sum_{i=1}^{n_{g t-1}^{E x i t}}\left\{s_{i g t-1} \times\left[p_{i g t-1}-\bar{P}_{g t}\right] \mid s_{i g t-1} \times\left[p_{i g t-1}-\bar{P}_{g t}\right]>0\right\}}_{\text {Exit effect }}
\end{aligned}
$$


Now, substituting (A.42) into (A.34), we get

$$
\begin{aligned}
\Delta P_{t} & =\underbrace{\sum_{g=1}^{G} \Delta P_{g t} \times \bar{s}_{g t}}_{\text {Within group effect }}+\underbrace{\sum_{g=1}^{G}\left[\bar{P}_{g t}-\bar{P}_{t}\right] \times \Delta s_{g t}}_{\text {Between group effect }} \\
& =\underbrace{\sum_{g=1}^{G}\left[V C_{g t}^{W}-V D_{g t}^{W}\right] \times \bar{s}_{g t}}_{\text {Within group effect }}+\underbrace{\sum_{g=1}^{G}\left[\bar{P}_{g t}-\bar{P}_{t}\right] \times \Delta s_{g t}}_{\text {Between group effect }}
\end{aligned}
$$

We then define value added creation in group $g$ at time $t, V C_{g t}$, as the sum of of the value creation part in the within group effect in (A.45) and the between group effect in (A.45) when it is positive:

$$
V C_{g t}=V C_{g t}^{W}+\left\{\left[\bar{P}_{g t}-\bar{P}_{t}\right] \times \Delta s_{g t} \mid\left[\bar{P}_{g t}-\bar{P}_{t}\right] \times \Delta s_{g t} \geq 0\right\}>0 .
$$

Moreover, we define value added destruction in group $g$ in time $t, V D_{g t}$, as the sum of of the value destruction part in the within group effect in in (A.45) and the between group effect in in (A.45) when it is negative:

$$
V D_{g t}=V D_{g t}^{W}-\left\{\left[\bar{P}_{g t}-\bar{P}_{t}\right] \times \Delta s_{g t} \mid\left[\bar{P}_{g t}-\bar{P}_{t}\right] \times \Delta s_{g t}<0\right\}>0
$$

Finally, we define the net value added creation in group $g$ in time $t, N e t_{-} V C_{g t}$, as

$$
N e t_{-} V C_{g t}=V C_{g t}-V D_{g t}
$$

Using (A.46)-(A.48) in (A.45), we then have

$$
\begin{aligned}
\Delta P_{t} & =\sum_{g=1}^{G}\left[V C_{g t}-V D_{g t}\right] \\
& =\sum_{g=1}^{G} N e t_{-} V C_{g t}
\end{aligned}
$$


Finally, summing over all time periods, we obtain

$$
\begin{aligned}
\Delta P & =\sum_{t=1}^{T}\left(\sum_{g=1}^{G} N e t_{-} V C_{g t}\right) \\
& =\sum_{t=1}^{T}\left(\sum_{g=1}^{G}\left(V C_{g t}-V D_{g t}\right)\right)
\end{aligned}
$$

Hence, from (A.49) the change in labor productivity, $\Delta P$, can be written as the sum of the net value added creation (over all groups and periods), which equals the difference in the corresponding sums of value added creation and value added destruction. 


\section{Tables and Figures}
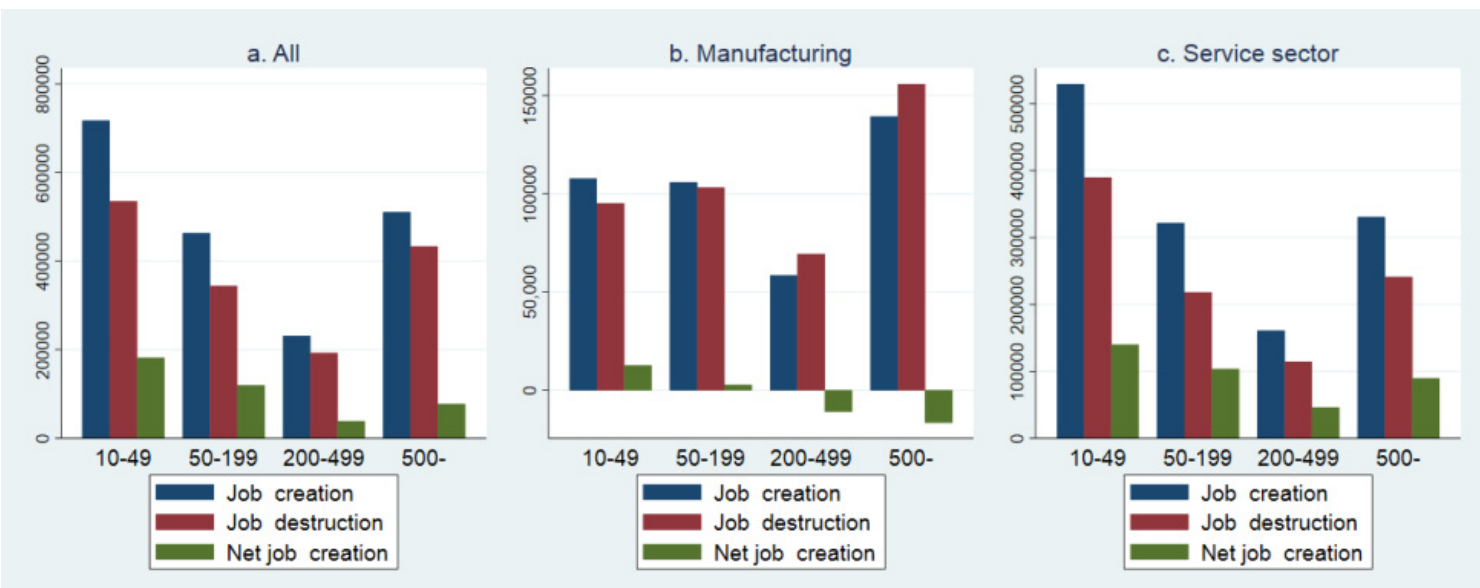

Figure 1. Job dynamics in the Swedish business sector separated by firm size and sector, 1996-2013; See Section 2.1 and the Appendix for further details.
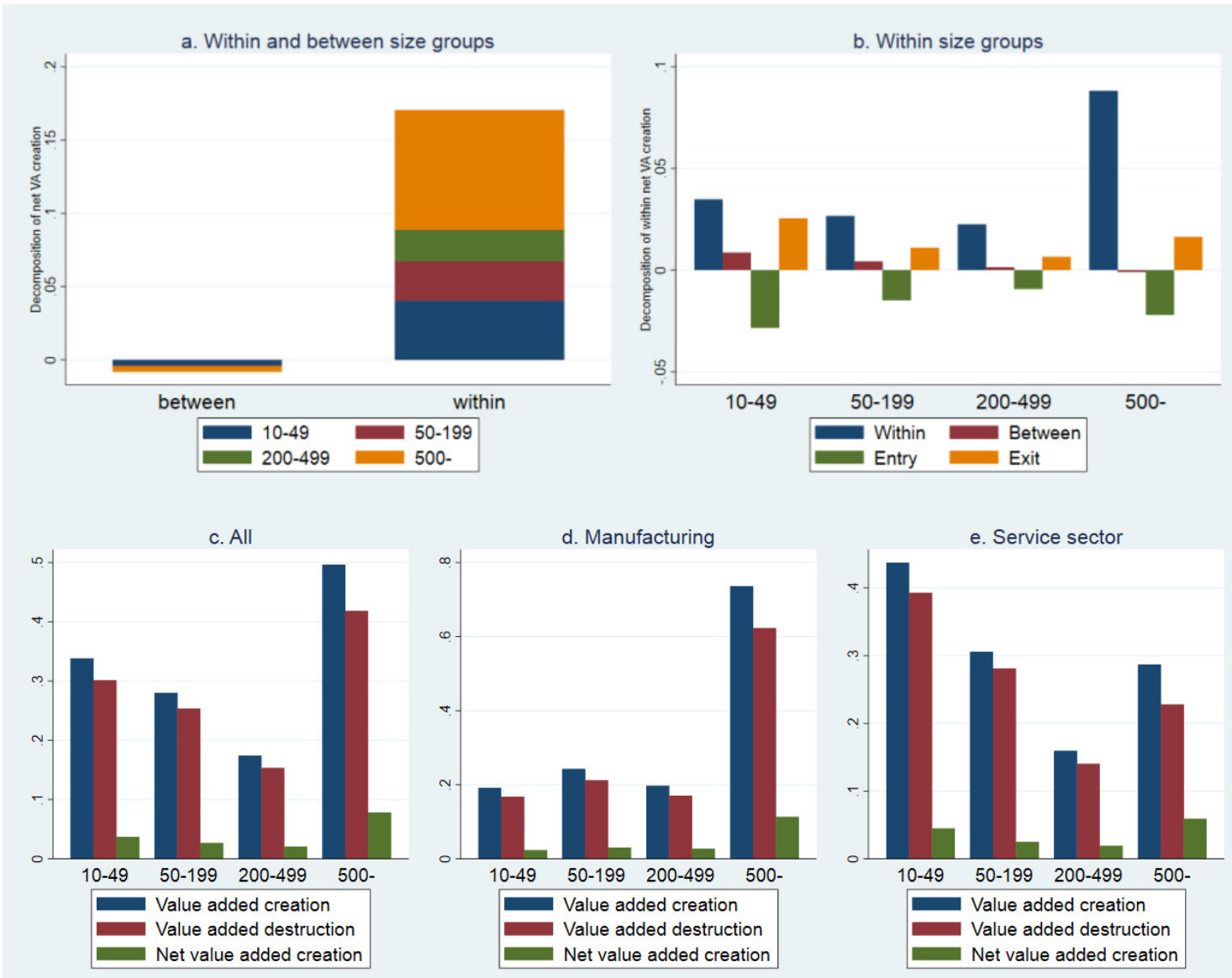

Figure 2. Productivity (net value added creation) in the Swedish business sector separated by firm size and sector, 1996-2013; productivity is expressed in millions of SEK per employee. See Section 2.2 and the Appendix for further details. 

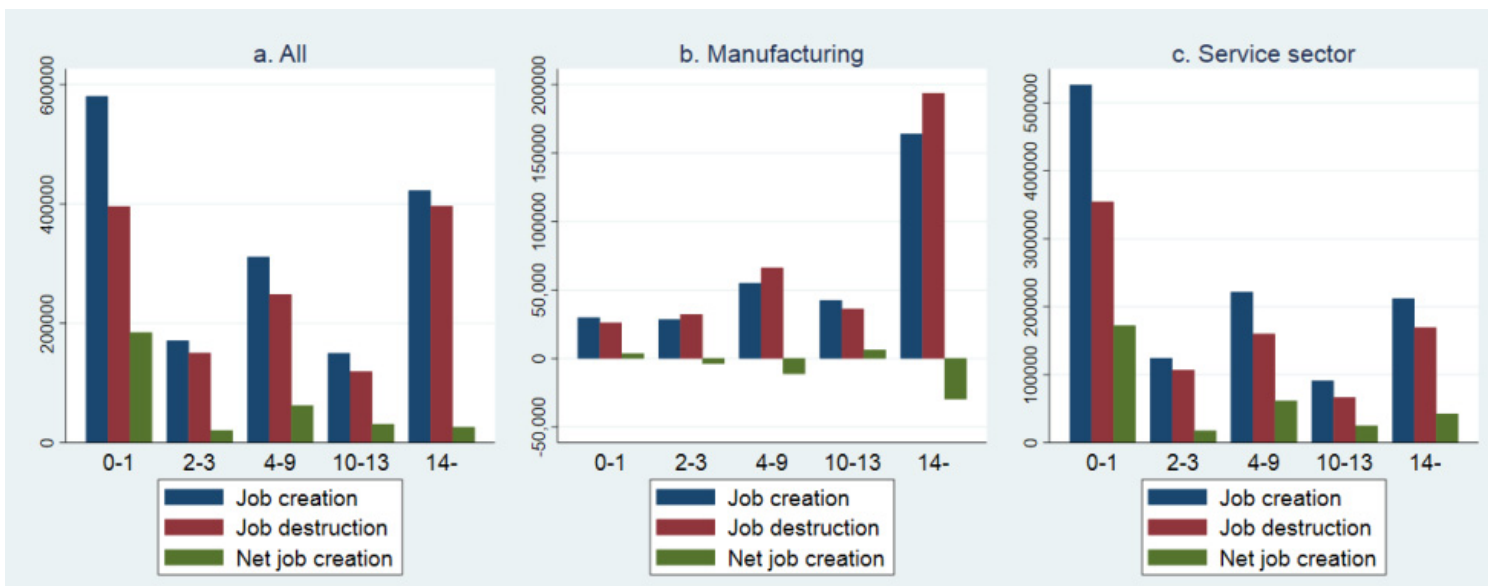

Figure 3. Job dynamics in the Swedish business sector separated by firm age and sector, 2000-2013; See Section 2.1 and the Appendix for further details.
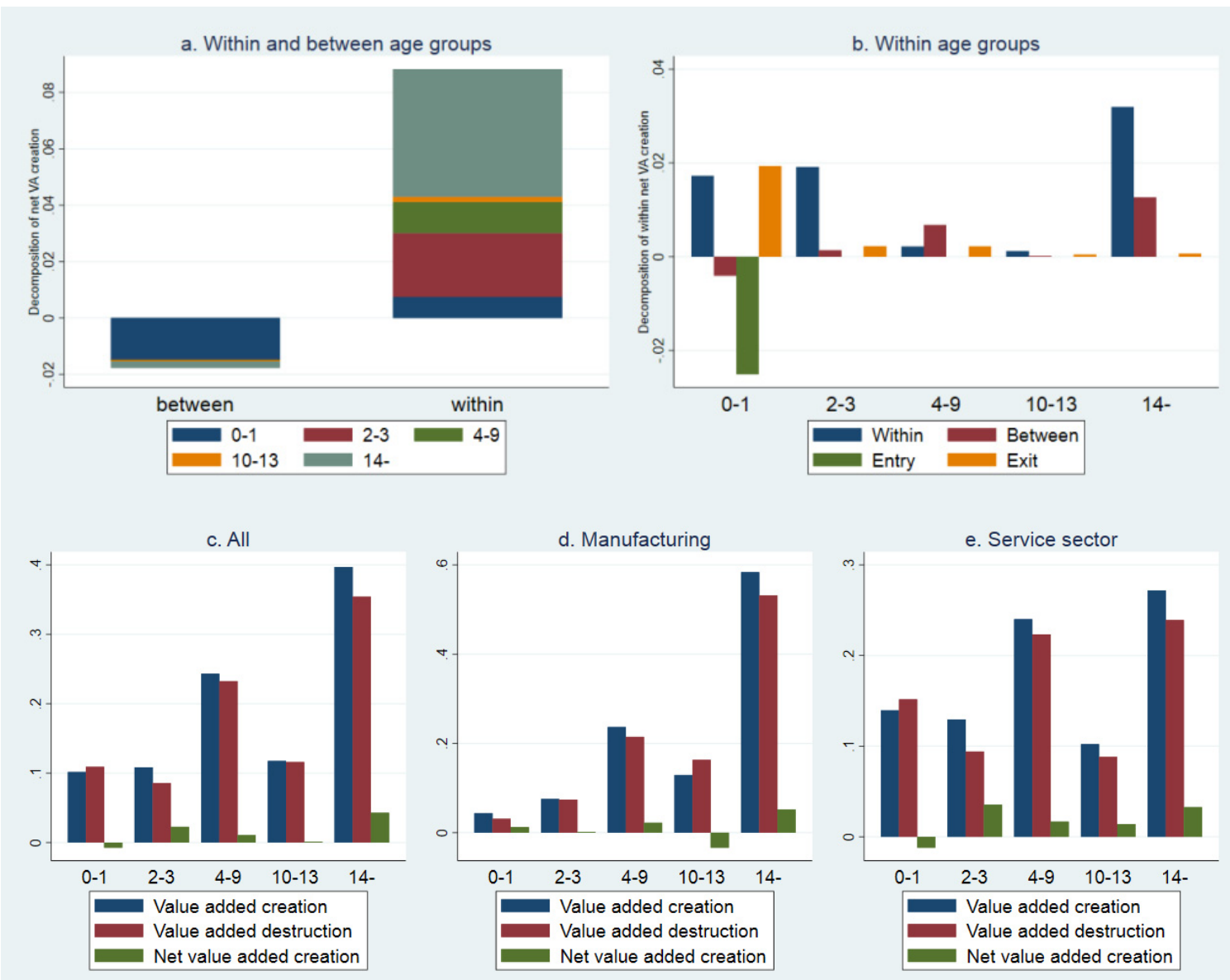

Figure 4. Productivity in the Swedish business sector separated by firm age and sector, 2000-2013; productivity is expressed in millions of SEK per employee. See Section 2.2 and the Appendix for further details. 

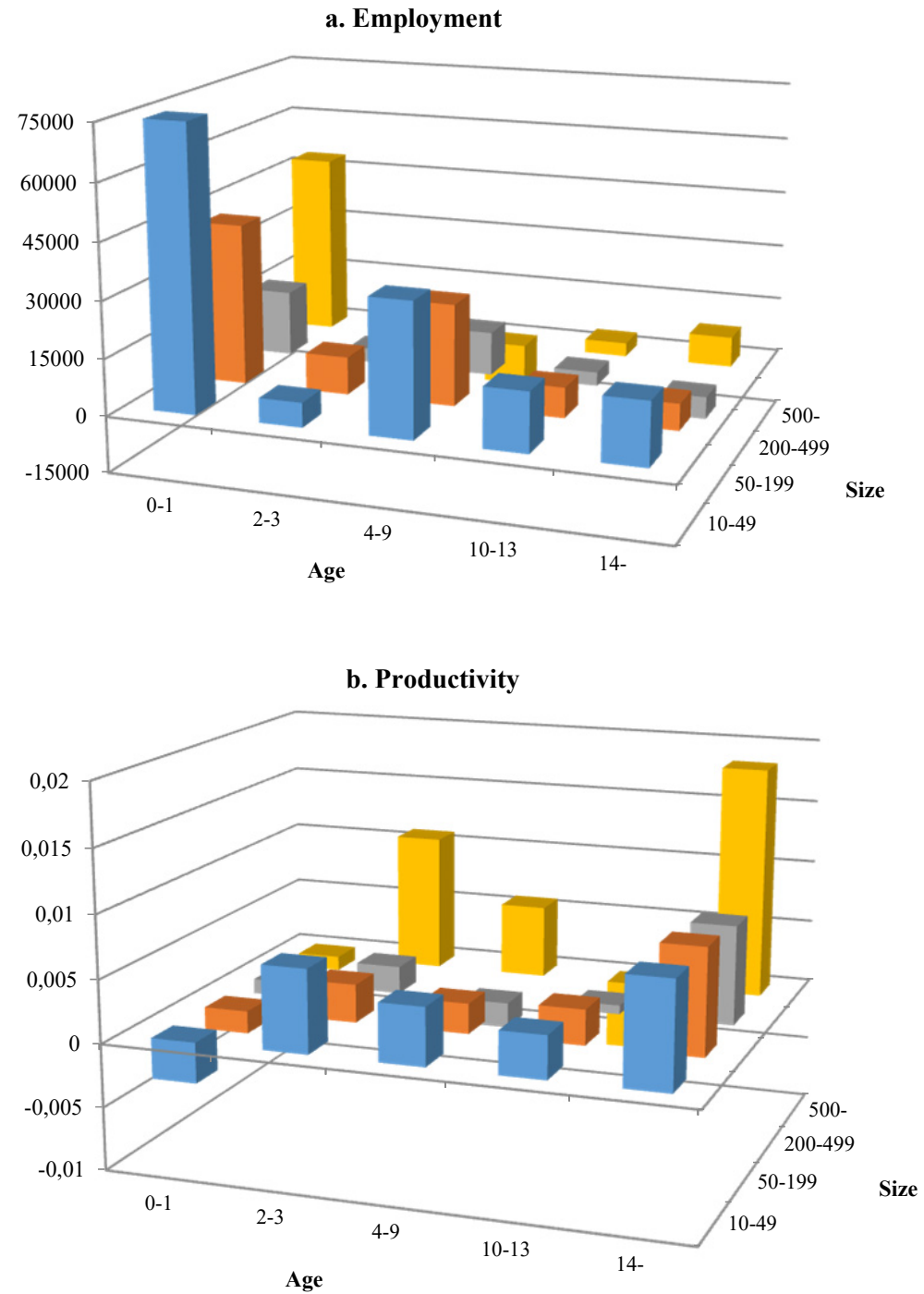

Figure 5. Employment (net job creation) and productivity (net value added creation) in the Swedish business sector separated by firm size and firm age 2000-2013; productivity is expressed in millions of SEK per employee. See Section 2 and the Appendix for further details. 


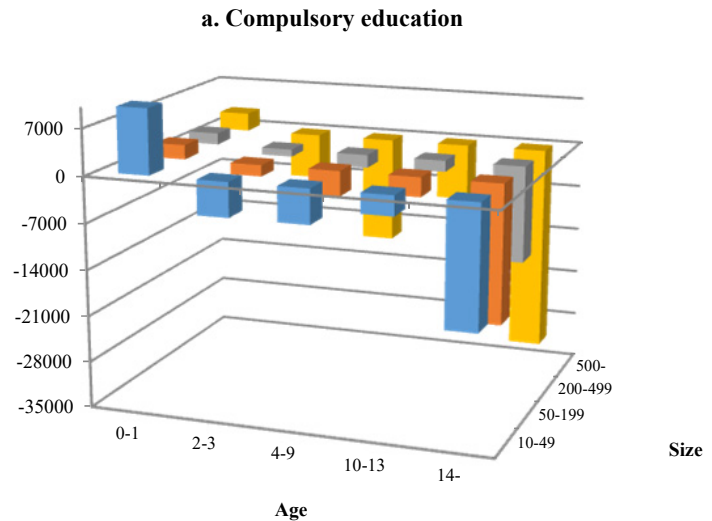

b. Secondary education

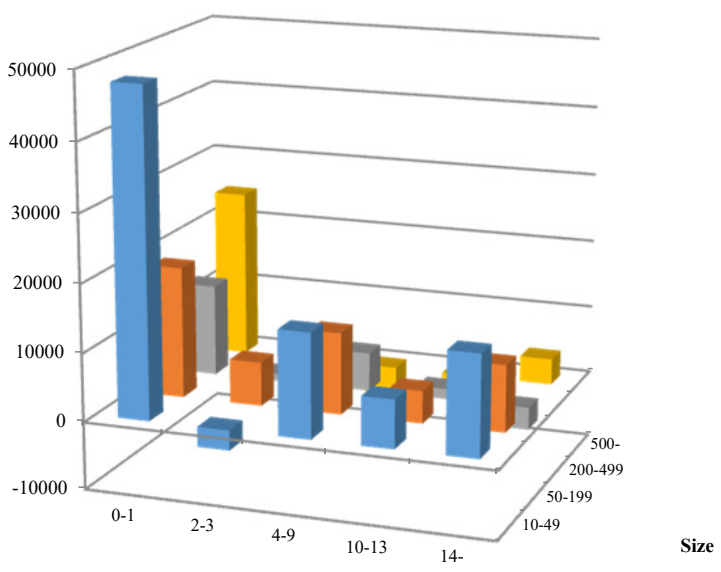

Age

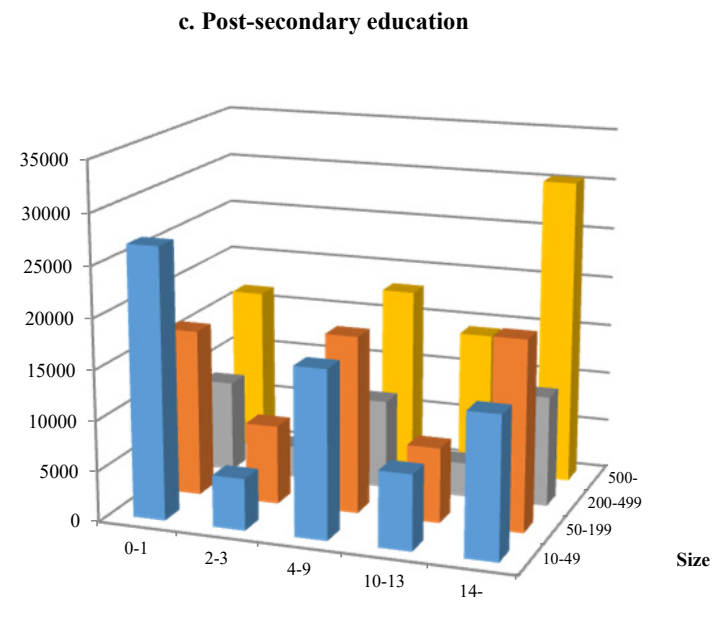

Age

Figure 6. Net job creation for individuals belonging to different education levels, separated by combinations of firm age and firm size, 2000-2013. 